\title{
Relationship Between Academic Performance and Perception of Healthy University Among Dental Students
}

\author{
Paulus Januar ${ }^{1}$ \\ \{paulusjanuar@dsn.moestopo.ac.id ${ }^{1}$ \} \\ ${ }^{1}$ Dental Public Health Department Faculty of Dentistry Prof Dr Moestopo (Beragama) University, \\ Jakarta, Indonesia
}

\begin{abstract}
Healthy University aspires to create a learning environment and organizational culture that enhances the health, well-being and sustainability of its community and enables people to achieve their full potential. Academic performance is the extent to which a student has achieved the educational goals. It was assumed that the students with high academic performance would have a good perception on healthy university concept. The objective of the study was to examine the relationship between academic performance and the perception of healthy university among dental students. The study was an analytical survey conducted to dental students of Prof Dr Moestopo (Beragama) University. Academic performance were calculated using Cumulative GPA (Grade Point Average) scores as a standard way of measuring academic achievement. The data on student perception of healthy university were gathered using a set of questionnaire. The results showed that both the students' academic performance and the perception of healthy university were good. Results of the Pearson correlation showed a significant positive association between academic performance and perception of healthy university, $(\mathrm{r}(67)=0.447, \mathrm{p}=0.000)$. It was concluded that the academic performance influenced the perception of healthy university among dental students. This understanding can support the planning of promoting healthy university environment.
\end{abstract}

Keywords: student academic performance, healthy university

\section{Introduction}

Healthy university is an environmental setting for studenthealth and wellbeing. The settings approach reflects anecological model that health is a complex interactionbetween environmental, organisational andpersonal issues. The healthy settings approach focuses on to create contexts and environments that are supportive to health and wellbeing, and also at the same time appreciating that can contribute positively to performance and productivity.Based on healthy university concept, the university includes health issues within their educational process to improve the health of the community members[1,2].

In the implementation of healthy university concept, health promotion can be introduced into and embedded within theuniversity environment. Thus the focus forthe Healthy University is not only on identifying needs and encouraging behaviour change and diseaseprevention, but also on fostering health assets and strengthening resources for health, wellbeing andhuman flourishing [3]. 
In the context of ahealthy university, the whole systems approachis characterised by three overarching aims. Firstly, creating healthy, supportive andsustainable learning, working andliving environments for students, staffand visitors; secondly, increasing the profile of health andsustainability in the university's coreactivties - its learning, research andknowledge exchange; thirdly, connecting with and contributing tothe health, wellbeing andsustainability of the widercommunity. A healthy universityprogramme is usually comprised of a range of many activities, interventions and projectswhich will invlove the needs of faculty, students,community and relevant stakeholders [4].

According to The Charter of International Conference of Health Promoting Universities and Colleges[2], healthy university environment promotes universities and colleges to enhance the success of institutions, create campus cultures of healthy environment, improve the health of the people in the campuses, and strengthen the ecological, social and economic sustainability of thecommunities and wider society.Healthy university aspires to create a learning environment and organisational culture that enhances the health, well-being and sustainability of its community and enables people to achieve their full potential. The Charter has two calls to action for higher education institutions. Firstly, embed health into all aspects of campus culture, across the administration,operations and academic mandates. Secondly, lead health promotion action and collaboration locally and globally.Universities have an important role in promoting health of the public through the integration of health in all aspectseducational institutions.

In South East Asian region, the Asean University Network (AUN) [5] organized an international meeting on health promoting university in Thailand on August 2016. The result of the meeting was a comprehensive document namely the "AUN Healthy University Framework". The framework provides a broad theoritical basis and practical approaches for any university to implement healthy university concept intothe institution. According to the framework, the overall components of healthy university are a set of 9 principal determinants: (1) Healthy university polices, (2) Safe buildings and safe, clean environment, green environments, (3) Health promotion services, counseling and advisory support (4) Equal opportunities including disability friendly, (5) Health promotion curriculum and cocurriculum (6) Capacity building on health promotion, (7) Health promotion research, (8) University volunteerism, and (9) Budgetary support for healthy university programme.

A systematic review revealed that healthyuniversity approach was firstpromoted in England in the mid-1990s. Since then, similar initiatives were developed inother countries in Europe, Asia, and Latin America, and there was a growing interest in applying the healthy settings approach within the universities[5].

Suárez-Reyes et al.[6], explored the way in which 54 universities from 25 countries across the world implemented the healthy promoting university. The results showedthe adherence by most university to the components of the healthy promoting university framework: use of the whole systems approach; multiservice collaboration; recognition by the university authorities; funding availability; membership of a healthy promoting network and evaluation of the initiative.

Academic performance or academic achievement is the extent to which a student has achieved their short or long-term educational goals. More broadly, academic performance for all students is one of the key evaluation of the university.Academic performance is characterized by the overall Cumulative GPA (Grade Point Average).Grade Point Average (GPA) is a way to measure academic performance[7].

Al-Ansari and El Tantawi [8] studied the educational environment and academic performance, and concluded that the students' academic performance affected various aspects 
of perceiving the educational environment. One of the environmental setting for the student is healthy university [1].

Therefore it was important to know whether the students with high academic performance would also have a good perception of healthy university concept, especially among dental student since they were the incoming health workforceswith the potential to influence the conditions affecting health and wellbeing in a multitude of ways. The objective of the study was to explore the relationship between academic performances and the perception of healthy university among dental students of Prof Dr Moestopo (Beragama) University, Jakarta Indonesia.

\section{Methods}

The study was an analytical surveyusing the correlation research design because the study was intended to investigate the relationship between academic performances and the perception of healthy university. The samples were dental students of Prof Dr Moestopo (Beragama) University that were selected using purposive sampling method.

Academic performance was measured using Cumulative GPAscores as a standard way of measuring academic achievement[7]. The data of cumulative GPA of the students were extracted from database and archive of educational services office of the university.

The data of students' perception of healthy university were gathered using a questionnaire comprised of 15 closed questions. The questionnaire wasdeveloped as amodification from Healthy University Self Review Tolls [9].The UK Healthy Universities Network has formulated an online toolkit, which includes a Self-Review Tool, intended to enable universities to assess what actions they need to take to develop as a healthy university [10].The questionnaire structured under five headings that reflect the key areas of a Healthy University viz. :(1) Leadership and Governance, (2) Service Provision, (3) Facilities and Environment, (4) Communication and Information; and (5) Academic, Personal, Social and Professional Development [9]. The reliability of the questions was confirmed using a pilot study on 30 students, and for the present study, Cronbach's alpha of 0.76 revealed acceptable reliability coefficients. To ensure content validity of the research questionnaire, it was presented to 3 dental public health experts, and based on their views and comments, the necessary alteration were made. Informed consent form wasattached to the questionnaire that explained the purpose ofthe study andissues of confidentiality of information gathered, and all subjects were agreed to participate in the study.Ethical clearance toconduct this study gained from the Research Ethics Commission of Faculty of Dentistry Prof Dr Moestopo (Beragama) University.

Pearson correlation was performed to determine the relationship between students' academic performance and students'perception of healthy university. The data were analyzed using computer statistical software and $\mathrm{p}<0.05$ was considered statisticallysignificant.

\section{Results and Discussion}

The study was carried outon January 2018 at Faculty of Dentistry Prof Dr Moestopo (Beragama) University, Jakarta - Indonesia. Using purposive sampling method and based on sampling size formula, a total of 67 dental students studying academic (pre-clinical) program and professional (clinical) programwere selected and enrolled as the subjects of the study. The subjects comprised of 54 female and 13 male students. The proposition of female and male in this study was according to the proportion of student population. The mean age of the subjects was 20.24 years old with a range of 19 to 24 years old. 
The cumulative grade point average (GPA) was used in in measuring students' academic performance/achievement [7]. The GPA was based on a 4-point scale $(A=4.00, B=3.00$, $\mathrm{C}=2.00$, and $\mathrm{D}=1.00$ ) and the students recorded their exact cumulative GPA, for example 2.78. The cumulative GPA of 2.0 was the minimum passing grade.A grade of less than 2.0 in a course was given when the achievement is unsatisfactory according to established course guidelines.Based on the range 1 to 4 and the criteria of passing grade, then in this study, the cumulative GPA scores were categorized into: poor $(<2)$, fair $(2.01-2.5)$, Good $(2.51-3)$, VeryGood $(3.01-3.5)$, and excellent $(3.51-4)$. Table 1 presented the academic performance of the students.

Table 1. Students' Academic Performance

\begin{tabular}{ccc}
\hline Cumulative Gpa & Frequency & Persentage \\
\hline Poor & 3 & $4.5 \%$ \\
Fair & 22 & $32.8 \%$ \\
Good & 21 & $31.3 \%$ \\
Very Good & 12 & $17.9 \%$ \\
Excellent & 9 & $13.4 \%$ \\
Total & 67 & $100 \%$ \\
\hline $\mathrm{n}=67$ & &
\end{tabular}

The results of academic performance in table 1 showed that, the academic performance of most of the students were fair $(32.8 \%)$ and good $(31.3 \%)$. The mean cummulative GPA was $2.81(\mathrm{SD}=0.54)$, with the range of 1.8 to 3.9 . The mean score of cummulative GPA of 2.81 was in the category of good.

In this study, cumulative GPAwas used as a measure of academic performance toassess the versatility of the students at the universitylevel.Measuring academic performance would provide key information about students' mastery of the study. The GPAsystem is used as formal assessment of students' academic performance by the universities. The GPA data are usedby universities besides to measure learning outcomes, also for comparative assessmentswith other institutions [7]. Good academic performance as the results of this study could be used to other universities as the comparison of student versatility. In the field of higher education, various factors related to learning process had been studied and this study assessed the relationship of learning process and healthy envoronment in the campus.

Questionnaire was used in measuring students' perception of healthy university. The questionnaire on student perception of healthy university was based on an understanding of the whole system approach, which recognized the interrelationships and interconnectedness of different elements of the university system, and emphasized the importance of the interactions between people, their behaviours and their environment [1,2, and 9]. The questionnaire was a modification of Healthy University Self Review Tolls developed byThe UK Healthy Universities Network [9]. Based on the study of Holt et al. [10], the Self-Review Tool had provided a crucial start for universities undertaking the journey towards becoming a healthy university. The questionnaire was consisted of 15 Likert style questions, and each question was scored 0 to 4 , from strongly agree tostrongly disagree. In analyzing students' perception of healthy university, from the range of total score of 0 to 60 , the scores were categorized into: Very bad $(0-7.5)$, Bad (7.6- 22.5), Neutral/do not know (22.6 - 37.5), Good (37.6- 52.5), and Very good (52.6 -60). Table 2 presented the students' perception of healthy university. 
Table 2. Students' Perception Of Healthy University

\begin{tabular}{ccc}
\hline Perception & Frequency & Persentage \\
\hline Very bad & 0 & $0 \%$ \\
Bad & 0 & $0 \%$ \\
Neutral/do not know & 13 & $19.4 \%$ \\
Good & 37 & $55.2 \%$ \\
Very good & 17 & $25.4 \%$ \\
Total & 67 & $100 \%$ \\
\hline $\mathrm{n}=67$ & &
\end{tabular}

The results on the perception of healthy university showed that, most of the students' perception were good $(55, .2 \%)$ and very good $(25.4 \%)$. The mean score of the students'perception of healthy university was 40.89 ( $\mathrm{SD}=8.76)$, and the range was 24 to 55 . The mean score of the students'perception of healthy university of 40.89 was in the category of good.

Pearson correlation was performed to determine the relationship between students' academic performance and students' perception of healthy university. The results showed that there was a significant positive correlationbetween students' academic performance and students' perception of healthy university, with $\mathrm{r}(67)=0.447$, and $\mathrm{p}=0.000$. It meant that the increase in academic performance would increase the students' perception of healthy university, and vice versa.

Particular characteristic of the subjects of the study, that they were dental students. In their educational process based on dental education curriculum, in the university they already studied public health and other health/medical sciences, besides dental sciences as their main study [11]. This particular characteristic as dental students might also influence their perception on healthy university as well.

The good perception of healthy university affected the students' health and wellbeing. Study by Holt and Powell [1] about the student perceptions of a healthy university concluded that to the students, the concept of a healthy university was more likely to value and prioritise health and wellbeing, in the short andlong term through to their adult lives. The finding of this study revealed that the students were enthusiastic about connecting their core study of dentistry to the healthy university agenda and confirmed that they would, in principle, be supportive of healthy university implementation.

The universities are leading institutions in the society as they have an important role in building capacity of people through various academic programs [2]. Study by Holt and Powell [1] to 3,683 students in England concluded that going to university was a transitional period that shaped the conditions for the acquisition of their healthy lifestyles. The healthy university was a setting for the promotion of health and wellbeing to the students. As the consequences of the implementation of healthy university, it would contribute to the formation of health behavior of the students $[2,4]$. In turns, health behavior affected academic performance ofthe students. Several studies by Langford et al. [12], Peltzer K, and Pengpid [13] and Rehman et al. [14] showed that, there was a positive correlation between healthy behaviors and academic performance.

The goal of the present study was to examine the relation between students' academic performance and their perceptions of healthy university. A pearson correlation wasused to determine the relationship. The results showed that there was a significant correlation between students' academic performance and students' perception of healthy university, although was not very strong, with the correlation coefficient $r=0.447$. The significant correlation indicated 
that the learning process of the students would support the implementation of healthy university in the higher education institution.

In implementing healthy university, activities on university campuses such asteachinglearning, research, and community/public service can be performed moreefectively and eficiently if the variousgroups and sectors are physically, mentallyand socially well. The implementation of healthy university should be integrated in all activities of the institution and stakeholders. All constituents andsectors of the university should take part in implementation of healthy university $[1,2]$.

A systematic review by Reyes and Van den Broucke[15] on the implementation of healthy university concluded that, most of the universities work towards similar goals, yet that the way in which initiatives are implementeddepends on each university context.Strategies to facilitate adaptation to context include: stakeholder participation in planning andimplementation, adaptation of educational material and analysis of needs.As countries and cultures differ, the context forimplementing the approach also varies widely.Since health promotion interventions are moreeffective when they are adapted to context, and healthy promoting university initiatives should beadapted to local culture and organisationalcharacteristics.

Newton, Dooris,and Wills [16], based on their study on healthy university, demonstrated the importance ofviewing the organisation of university as a social system and offostering and nurturing the 'whole' by understandingand paying attention to the complex interactionsand interconnections between component parts. Only then health and wellbeing would be produced inthe university setting and began to infuse theuniversity system in its entirety, and be understoodas a valued means of maximising its performance asa rich and diverse community and centre of learning,research and enterprise.

Holt et al. [10] conducted surveys and focus groups discussion to collect data on healthy university concept on universities in England, Scotland and Wales. The study concluded that the concept of a healthy university could tailor its facilities and supportive environments to the needs of its students.According to Dooris, Wills, and Newton [3], because one of the aims of the healthy settings approach is to move health into the contexts ofeveryday life, it is important to understand how organisations such as universities work, in order toensure that health can become truly embedded.

Furthermore, by implementing healthy university will enhance the universities to perform their threeinterrelated functions, namely: education,research and public service. On the other hand, the advancement of healthy university will have theadded value of projecting a positive public image, and improvingthe quality of the university [2,5].

The current study had its limitations as well. This study was a crosssectionalsurvey in which self-assessment approach wasadopted. The sample included university students from asingle university and therefore the study's findings could notbe generalised externally. The study analyzed the impact of specificvariables viz. the academic performance on the students' perception of healthy university, but other variables that influenced the perception of the students were not been examined, so for furtherresearch, these variables could be analyzed.

Replications of the study with a welldistributedsample from various higher education institutions and analyze more other variables may produce more significant results.In order to progress the healthy universities implementation and embed it within public health policy and practice, further study will be very important. 


\section{Conclusion}

Underpinned by the universities settings and environment, this study examined the relationship between students' academic performance and students' perception of healthy university at the Faculty of Dentistry Prof Dr Moestopo (Beragama) University, Jakarta Indonesia. Both the academic performance of the students and their perception of healthy university were good. There was a significant relationship between students' academic performance and students' perception of healthy university. The academic performance influenced the perception of healthy university among dental students. The learning process of the students would support the implementation of healthy university.

The resultsof this study can be used in the planning of academic health promoting universityinitiativesto meet the distinctive needs of students, and therefore contribute to the development of the university. Universities were seen as environmental settings that could influence the health of their membersthrough working conditions, and patterns of activities.Health is product of interdependencebetween people and their environments. Thus healthy environmentin form of healthy university were prerequisitesfor the promotion of health.In the future to progress the healthy universities effectively, it is imperative for conducting furtherresearch in order to providea better understanding.

\section{References}

[1] M. Holt, and S. Powell, Healthy Universities: a guiding framework for universities to examine the distinctive health needs of its own student population, Perspectives in Public Health: January 2017 Vol 137 No 1, pp.53-58 (2017).

[2] International Conference Health Promoting Universities and Colleges,Okanagan Charter:An International Charter for Health Promoting Universities and Colleges, Okanagan, British Columbia, Canada, 2015,retrieved from: http://www.internationalhealthycampuses2015.com/, accessed March, 11, 2018.

[3] M.T. Dooris, J. Wills, and J. Newton, Theorizing healthy settings: a critical discussion with reference to Healthy Universities, Scandinavian Journal of Public Health, 42 (15 Sup). pp. 716, 2014, http://dx.doi.org/10.1177/1403494814544495.

[4] Healthy Universities Network, England,retrieved from: www.healthyuniversities.ac.uk, accessed March, 11, 2018.

[5] Asean University Network (AUN), AUN Healthy University Framework. Bangkok: AUN-Health Promotion Network, Mahidol University, Thailand pp. 2, 7-20 (2017).

[6] M. Suárez-Reyes, M.M. Serrano, and S. Van den Broucke, How do universities implement the Health Promoting University concept? Health Promotion International, day055, published: 23 July 2018, https://doi.org/10.1093/heapro/day055.

[7] Academic Achievement, retrieved

from: https://en.wikipedia.org/wiki/Academic_achievement, accessed March, 11, 2018.

[8] A.A. Al-Ansari, andM.M.A. El Tantawi,Predicting Academic Performance of Dental Students Using Perception of Educational Environment,Journal of Dental Education Volume 79, Number 3, pp. 337-344 (2015)

[9] M. Dooris, A. Farrier, S. Doherty, M. Holt, R. Monk, and S. Powell, the Healthy Universities Self-Review Tool: Whole System Impact, Health Promotion International: 33(3): pp 448-457 (2016).

[10] M. Holt, R.Monk, S. Powell, and M. Dooris, "Student perceptions of a healthy university," Public Health, Volume 129, Issue 6, pp 674-683 (2015) 
[11] Konsil Kedokteran Indonesia,Standar Kompetensi Dokter Gigi Indonesia, Jakarta: author, pp 8-20, 2015

[12]R. Langford, C. Bonell, H. Jones, T. Poulliou, S. Murphy, andWaters, the WHO health promoting school framework for improving the health and well-being of students and their academic achievement. Cochrane Database of Systematic Reviews 4, CD008958 (2014)

[13]K. Peltzer, and S.Pengpid, Health behaviour and self-reportedacademic performance among university students: aninternational study, Mediterr J Soc Sci 2014, 5 pp. 998 (2014)

[14]R. Rehman, A.Zafar, A.Mohib, M.Hussain, and A.Ali, Self-reported academic performance in relation to health behaviours amongBahria University students. JPMA, The Journal of the Pakistan Medical Association, 68(2), pp 195-199, 2018.

[15] M.S. Reyes, and S. Van den Broucke,Implementing the Health Promoting University approach inculturally different contexts: a systematic review Global Health Promotion, 23 Supp. 1: 46-56, 2016

[16]J. Newton, M. Dooris, and J. Wills, Healthy universities: an example of a wholesystemhealth-promoting setting. Global Health Promotion, 2016, 23 Supp. 1,pp 57-65 (2016) 